\title{
MEASUREMENTS IN SEPARATED AND TRANSITIONAL BOUNDARY LAYERS UNDER LOW-PRESSURE TURBINE AIRFOIL CONDITIONS
}

\author{
Ralph J. Volino \\ United States Naval Academy \\ Department of Mechanical Engineering \\ Annapolis, Maryland 21402 \\ Email: volino@usna.edu
}

\author{
Lennart S. Hultgren \\ National Aeronautics and Space Administration \\ Glenn Research Center at Lewis Field \\ Cleveland, Ohio 44135 \\ Email: hultgren@grc.nasa.gov
}

\begin{abstract}
Detailed velocity measurements were made along a flat plate subject to the same dimensionless pressure gradient as the suction side of a modern low-pressure turbine airfoil. Reynolds numbers based on wetted plate length and nominal exit velocity were varied from 50,000 to 300,000 , covering cruise to takeoff conditions. Low and high inlet free-stream turbulence intensities $(0.2 \%$ and $7 \%$ ) were set using passive grids. The location of boundary-layer separation does not depend strongly on the free-stream turbulence level or Reynolds number, as long as the boundary layer remains non-turbulent prior to separation. Strong acceleration prevents transition on the upstream part of the plate in all cases. Both free-stream turbulence and Reynolds number have strong effects on transition in the adverse pressure gradient region. Under low free-stream turbulence conditions transition is induced by instability waves in the shear layer of the separation bubble. Reattachment generally occurs at the transition start. At $R e=50,000$ the separation bubble does not close before the trailing edge of the modeled airfoil. At higher $R e$, transition moves upstream, and the boundary layer reattaches. With high free-stream turbulence levels, transition appears to occur in a bypass mode, similar to that in attached boundary layers. Transition moves upstream, resulting in shorter separation regions. At $R e$ above 200,000, transition begins before separation. Mean velocity, turbulence and intermittency profiles are presented.
\end{abstract}

\section{NOMENCLATURE}

$c_{f}$ skin friction coefficient

$C_{p} \quad$ pressure coefficient, $1-\left(U_{\infty} / U_{e}\right)^{2}$

$f \quad$ frequency

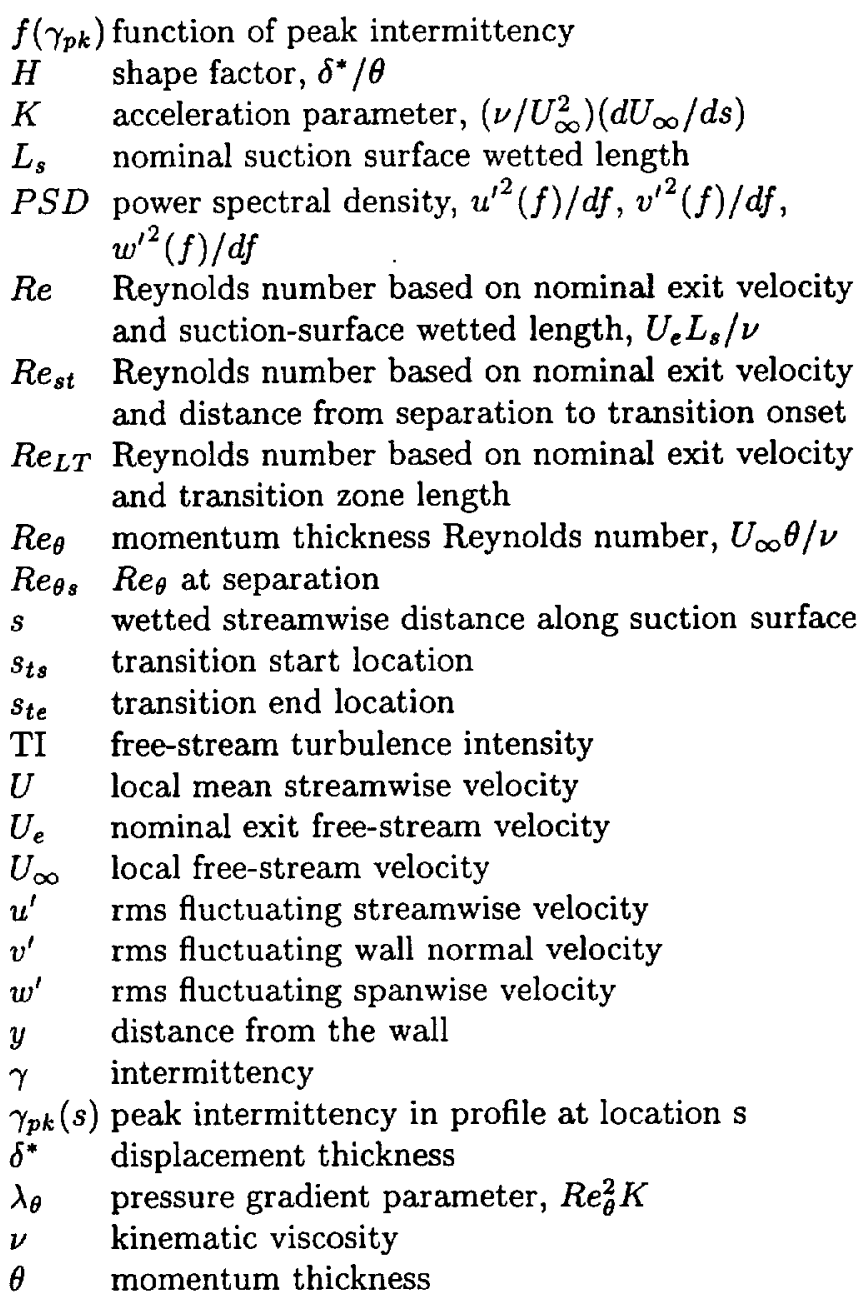




\section{INTRODUCTION}

Modern low-pressure turbine airfoils are subject to increasingly stronger pressure gradients as designers impose higher loading in an effort to improve efficiency. The adverse pressure gradients on the suction side of these airfoils can lead to boundary-layer separation, particularly under low Reynolds number conditions. Separation bubbles, particularly those which fail to reattach (referred to as "burst" bubbles), can result in a significant loss in lift, and, consequently, can cause a significant degradation of engine efficiency, e.g. Hourmouziadis (1989), Mayle (1991), and Sharma et al. (1994). A component efficiency drop of the order $2 \%$ may occur between takeoff and cruise conditions due to the lower Reynolds numbers at altitude for large commercial transport engines and could be as large as $7 \%$ for small military engines at high altitude. Accurate prediction of separation and reattachment is, therefore, crucial to improved turbine design.

The prediction of boundary-layer separation in the lowpressure turbine is complicated by the fact that a substantial fraction of the boundary layers on the airfoils may be transitional at cruise conditions (Mayle (1991)), whereas at takeoff conditions the boundary layers are generally more turbulent. Transition may begin before or after separation, depending on the Reynolds number and other flow conditions, and has a strong influence on subsequent reattachment. Further complicating the problem are the high free-stream turbulence levels in a real engine environment, the strong pressure gradients along the airfoils, the curvature of the airfoils, and the unsteadiness associated with wake passing from upstream stages. Because of the complicated flow situation, transition in these devices can take many paths that can coexist, vary in importance, and possibly also interact, at different locations and instances in time. Mayle (1991) classified the major paths of transition in turbomachinery as: 'natural' transition involving Tollmien-Schlichting waves-normally not considered a dominant feature in a real environment; 'bypass' transition - caused by high free-stream turbulence levels; 'separated-flow' transition-occuring in the shear layers of separation bubbles; and 'periodic-unsteady' transitionsuch as wake induced bypass transition. The performance degradation noted above indicates that existing engineering models are not quite adequate, particularly in cases of separated flow transition. To design against separation while still pushing toward higher loading, a better understanding of the flow physics clearly is needed.

The literature contains considerable information on boundary layer transition. Since transition may begin either before or after separation on a turbine airfoil, both attached and separated flow studies are pertinent. Most of the earliest work considered attached flow transition un- der low free-stream turbulence conditions. In this case, the transition sequence generally consists of a region of growth of linear Tollmien-Schlichting waves followed by nonlinear interactions and shortly thereafter breakdown to turbulence. At higher free-stream turbulence levels, the TollmienSchlichting waves do not appear to play a significant role and turbulent spots are created directly-this is known as bypass transition (Morkovin (1978)). Mayle (1991) and Volino and Simon (1995) provide reviews of work for low to moderate free-stream turbulence conditions from a turbomachinery point of view.

At free-stream turbulence levels above about $5 \%$, transition under zero pressure gradient conditions tends to be rapid, as shown by Kim et al. (1992). With strong acceleration, however, Volino and Simon (1997a) showed that extended transition zones are still possible, even at free-stream turbulence intensities (TI) as high as $8 \%$. At high TI the flow transitions between a highly disturbed non-turbulent state, which is characterized by high amplitude fluctuations at relatively low frequencies, and a fully turbulent state, which is characterized by fluctuations over a broad range of both high and low frequencies. The non-turbulent fluctuations are induced directly by the free-stream unsteadiness, while the turbulent fluctuations are due to near wall production. The transition region is characterized by intermittent switching between the two types of flow. These results are in agreement with the earlier study of Blair (1992) which documented bypass transition in accelerating flow with freestream turbulence levels up to about $5 \%$.

Separated flow transition has also been considered. Among recent studies, Malkiel and Mayle (1996) documented transition in the shear layer over a separation bubble. They report a transition similar to that in a free shear layer, in which instability waves break down to turbulence. Intermittency grew in a manner similar to that in an attached boundary layer, but with a higher turbulent spot production rate. Hatman and Wang (1999) considered cases on a flat plate under low free-stream turbulence conditions and various Reynolds numbers and adverse pressure gradients. They reported cases in which transition began over the separation bubble and cases in which separation occurred after the boundary layer was already transitional.

Documentation at moderate to high free-stream turbulence levels is more limited. Halstead et al. (1997) provide a study from a rotating cascade with multiple stages and TI characteristic of an actual low-pressure turbine. The adverse pressure gradients in this study, however, did not induce separation. Qiu and Simon (1997) documented separated flow transition at high TI in a study of the flow over a low-pressure turbine airfoil. Experiments were conducted using a single passage cascade utilizing the so-called 'Pak-B' airfoil shape, which is an industry supplied shape represen- 
tative of a modern aggressive design. This shape was also used by Murawski et al. (1997). Qiu and Simon (1997) considered inlet free-stream turbulence levels of $0.5 \%, 2.5 \%$ and $10 \%$, and Reynolds numbers (based on nominal exit velocity and suction-surface wetted length) ranging from 50,000 to 300,000 . They observed a variety of behaviors including short separation regions and complete transition at the higher Reynolds numbers and TI levels, and long separation bubbles and incomplete transition at the low Reynolds numbers and low TI levels. Sohn et al. (1998) conducted a similar study in the same wind tunnel as the present experiments. The facility has been altered, however, in both geometry and flow conditions for the present work.

Computational work has followed the experiments, including work by Dorney et al. (1999), Chernobrovkin and Lakshminarayana (1999), and Huang and Xiong (1998). More experimental work will provide insights for further improvements in computational models and test cases for code validation.

In the present study, the boundary layer on a flat plate is subject to a streamwise pressure gradient corresponding to that on the suction side of the 'Pak-B' airfoil. Choosing this pressure gradient allows comparison to the Qiu and Simon (1997) study, to determine the significance of convex curvature on the boundary layer behavior. Reynolds numbers from 50,000 to 300,0000 are considered, spanning the range from cruise to takeoff conditions. Cases with high (nominal $7 \%$ ) and low $(0.2 \%)$ inlet free-stream turbulence are documented. As will be seen later, these inlet TI levels in the present study correspond to about $0.2 \%$ and $2.5 \%$ in the test section when normalized with the exit velocity. Free-stream turbulence levels in low-pressure turbines could be as low as about $3 \%$ (Halstead et al. (1997)) on the suction side of the airfoils. The present high TI case, therefore, represents a realistic value. Further, a larger quantity of experimental data, with long time records at each measurement location, are acquired to provide more detailed documentation than in previous work.

The focus in this paper is on the mean velocities and turbulence statistics, as measured at stations throughout the boundary layer. From the velocity measurements, quantities such as intermittency, skin friction coefficients, transition start and end locations, and the locations of separation and reattachment are determined.

\section{EXPERIMENTAL FACILITY}

All experiments were conducted in a low-speed, recirculating wind tunnel. The wind tunnel was used in earlier studies, such as Sohn and Reshotko (1991). A blower capable of $4.72 \mathrm{~m}^{3} \mathrm{~s}^{-1}(10,000 \mathrm{CFM})$, with an $18.6 \mathrm{~kW}$ (25 HP) motor and variable speed controller, supplies air to a rect-

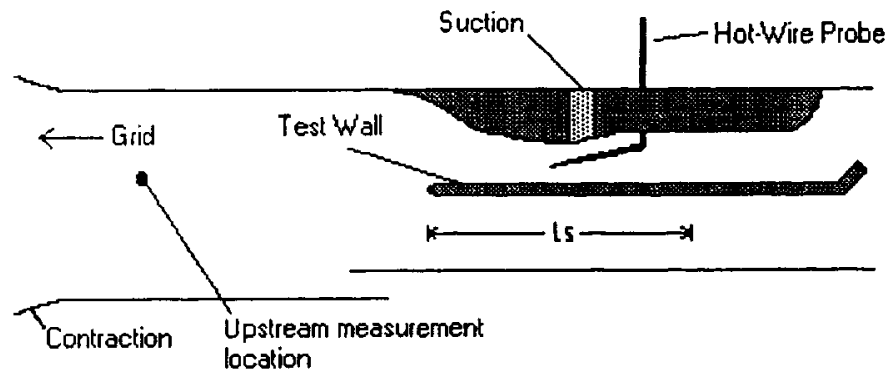

Figure 1. Schematic of the test section, side view, approximately to scale, $L_{s}=208 \mathrm{~mm}$ (wetted length, streamwise length is $206 \mathrm{~mm}$ )

angular channel of cross section $0.635 \mathrm{~m} \times 0.686 \mathrm{~m}$. The channel contains a series of screens and flow straighteners. Turbulence generating grids may be placed at the exit of the channel. In the present study, a coarse grid with $40 \%$ blockage, constructed with $50 \mathrm{~mm}$ wide, $13 \mathrm{~mm}$ thick (in the streamwise direction) vertical and horizontal bars, was used for the high TI case. Grid spacing is $178 \mathrm{~mm}$. For the low TI case, no grid was used. Just downstream $(29 \mathrm{~mm})$ of the grid location is an $0.914 \mathrm{~m}$ long, two-dimensional contraction, which reduces the flow area to $0.178 \mathrm{~m} \times 0.686$ $\mathrm{m}$. The long dimension is horizontal, the shorter is vertical. Following the contraction is an $0.245 \mathrm{~m}$ long straight section at the end of which is an upstream facing double bleed-scoop, located at the bottom of the channel, that further reduces the vertical dimension to $0.152 \mathrm{~m}$. Following this is a rectangular channel which serves as the test section. A side view schematic of the test section is shown in Figure 1.

A $12.7 \mathrm{~mm}$ thick horizontal Plexiglas plate with a $4: 1$ elliptical leading edge is mounted with its top surface at the vertical center of the channel, spanning the $0.686 \mathrm{~m}$ width, and with its leading edge $54 \mathrm{~mm}$ downstream of the beginning of the test section. The leading edge is, hence, $0.299 \mathrm{~m}$ downstream of the end of the contraction and 1.242 $m$ downstream of the grid location. The upper surface of the plate is the test wall for the experiments. A two-dimensional contoured shape is attached to the wall opposite the test wall to produce the desired pressure gradient along the test wall. The shape of the top wall was determined through experimental trial and error. A contoured shape from a previous study was initially tested and then built up until the pressure profile along the test wall matched the 'Pak- $\mathrm{B}$ ' airfoil profile.

In a cascade experiment, favorable pressure gradients prevent separation on the pressure side of the airfoils. In the present situation, however, suction is needed to insure that the flow remains attached on the contoured wall, and separates only on the test wall. Suction was applied through 
Table 1. Station locations.

\begin{tabular}{|c|c|c|c|c|c|c|c|}
\hline Station & 1 & 2 & 3 & 4 & 5 & 6 & 7 \\
$s / L_{s}$ & 0.28 & 0.33 & 0.39 & 0.45 & 0.51 & 0.57 & 0.63 \\
\hline Station & 8 & 9 & 10 & 11 & 12 & 13 & 14 \\
$s / L_{s}$ & 0.69 & 0.75 & 0.81 & 0.88 & 0.94 & 1.00 & 1.06 \\
\hline
\end{tabular}

holes along a $30 \mathrm{~mm} \times 0.686 \mathrm{~m}$ strip in the contoured wall, just downstream of the throat (position of maximum freestream velocity). A blower with an $0.75 \mathrm{~kW}$ (1 HP) electric motor and variable speed controller was used to produce the suction. The blower speed was adjusted for each Reynolds number considered, to prevent separation (as indicated by tufts attached to the contoured wall) and to produce the desired minimum pressure along the test plate at the throat. In addition, the contoured wall was covered by sandpaper upstream as well as a short distance downstream of the suction slot to promote a turbulent boundary layer on that surface via tripping.

Downstream of the test section, the flow entered a diffuser, then was routed through filters and a heat exchanger (cooler) before returning to the blower. The latter, of course, is needed to keep the wind-tunnel operating temperature from drifting.

\section{Instrumentation}

Streamwise velocity was measured using a single sensor hot-wire probe with a $5 \mu \mathrm{m}$ diameter platinum wire. The probe was inserted through a slot in the spanwise center of the top wall of the test section, and could be traversed in the streamwise direction and normal to the test wall. Traversing was accomplished using stepper motors controlled by the same computer used for data acquisition. Velocity profiles were acquired at the fourteen streamwise stations listed in Table 1. Each profile consisted of 55 to 57 points spaced normal to the wall, with finer spacing closer to the wall. Voltage data were acquired from the constanttemperature anemometer using a 16 bit digitizer, controlled through an IEEE 488 interface bus with a computer. At each measurement location, $53 \mathrm{~s}$ long time records were acquired consisting of just over 1 million $\left(1,048,576=2^{20}\right)$ data points collected at a $20 \mathrm{kHz}$ sampling rate using an anti-aliasing $10 \mathrm{kHz}$ low-pass filter before sampling. Uncertainty in mean and fluctuating velocities is $5 \%$, which is primarily due to bias error resulting from calibration uncertainty. Bias errors cancel when the velocities are normalized on the free-stream velocity, resulting in $3 \%$ uncertainty in the normalized quantities.

Upstream velocities were measured just after the con-
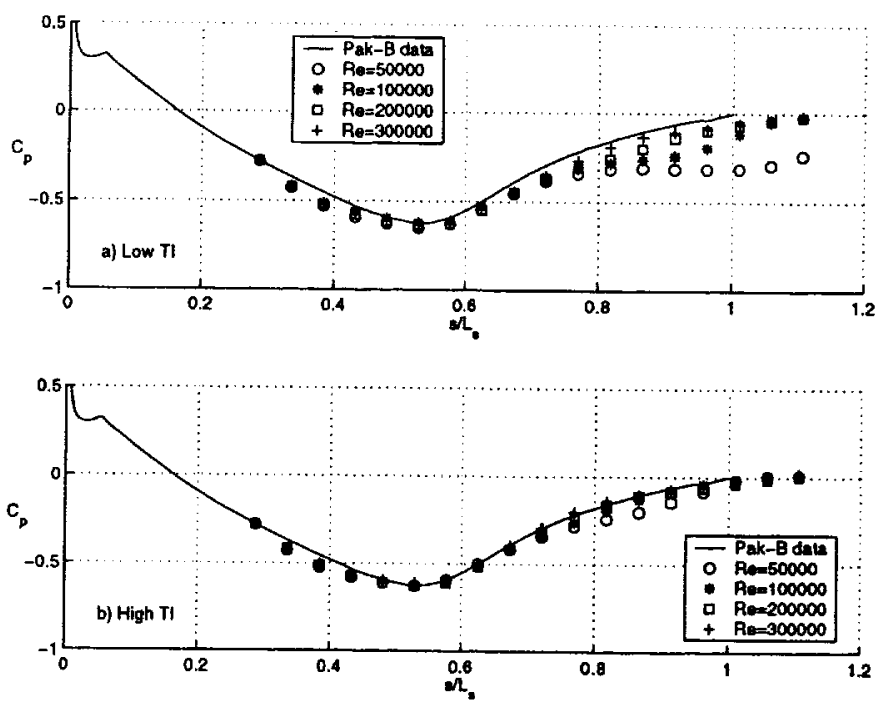

Figure 2. $C_{p}$ profiles: a) Low $\mathrm{TI}, \mathrm{b}$ ) High $\mathrm{TI}$

traction, $236 \mathrm{~mm}$ upstream of the leading edge of the test wall, using a cross-wire probe which was inserted in two orientations to obtain all three velocity components.

\section{RESULTS}

Experimental data were acquired with inlet TI of $0.2 \%$ and $7 \%$ and Reynolds numbers of 50,000, 100,000, 200,000 and 300,000 , for a total of eight cases. The focus in this paper is on the $R e=50,000$ and 300,000 cases at both high and low TI. Details of all cases are available in Hultgren and Volino (2000). Streamwise pressure profiles for all cases are shown in Figure 2 along with the expected profile for the suction side of the 'Pak-B' airfoil. The pressure coefficients, $C_{p}$, were computed from free-stream velocity measurements at a fixed height above the test wall. The streamwise distance is normalized on the nominal suction surface length. The section of the test plate which represented the airfoil is $208 \mathrm{~mm}$ long, while the actual plate is $356 \mathrm{~mm}$ long. The last measurement station is downstream of the point which represents the trailing edge of the airfoil. The pressure profiles upstream of the throat are in good agreement with the 'Pak-B' profile for all cases. Downstream, the agreement is good for the high $R e$, high TI cases. At the lower Reynolds numbers, the $C_{p}$ values indicate separation. At the low $\mathrm{TI}$ and $R e=50,000$, the boundary layer does not appear to reattach.

Free-stream spectra were computed from the cross-wire measurements at the exit of the contraction. Figure 3 shows the upstream free-stream spectra at $R e=300,000$ for the high and low TI cases. At the low TI, the turbulence inten- 


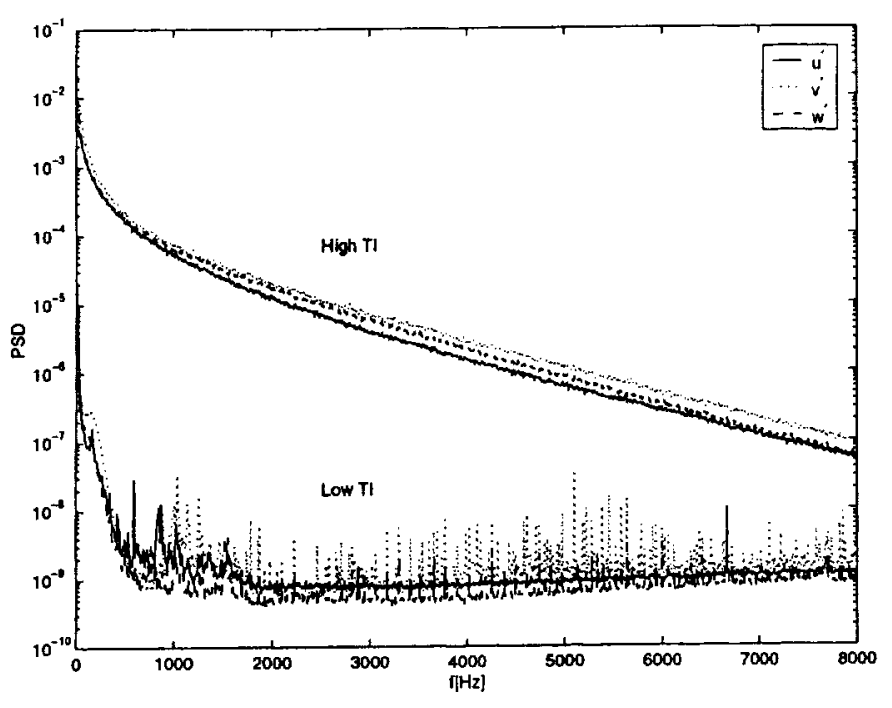

Figure 3. Free-stream spectra at contraction exit, $\mathrm{Re}=300,000$

sities in $u^{\prime}, v^{\prime}$ and $w^{\prime}$ are $0.3 \%, 0.13 \%$ and $0.08 \%$ respectively at all Reynolds numbers. Most of this TI is due to low frequency streamwise unsteadiness, as opposed to turbulent eddies. Downstream, the TI remains at about $0.2 \%$, despite the strong acceleration over the leading section of the test wall. At the high TI, the upstream turbulence intensities for the 50,000 Reynolds number case are $5.0 \%, 7.9 \%$ and $6.3 \%$ in $u^{\prime}, v^{\prime}$ and $w^{\prime}$. These quantities are $5.8 \%, 9.7 \%$ and $7.7 \%$ for the $R e=300,000$ case. The lower value in $u^{\prime}$ compared to $v^{\prime}$ and $w^{\prime}$ is due to the streamwise straining in the contraction, downstream of the grid. The integral length scales are $20 \mathrm{~mm}, 40 \mathrm{~mm}$ and $30 \mathrm{~mm}$ as determined from the $u^{\prime}, v^{\prime}$ and $w^{\prime}$ spectra. The integral scales are comparable to the width of the bars of the grid, and are representative of the large eddies in the free-stream. The integral scales did not vary significantly with the Reynolds number. Downstream, over the test wall, the TI drops to about $2.5 \%$. This is in part due to decay of the free-stream turbulence, but is mainly due to the increase in mean free-stream velocity as the flow is accelerated. The ratio of the free-stream velocity at the exit of the contraction to the velocity in the throat is 0.45. Qiu and Simon (1997) had the same ratio of inlet to throat velocity in their cascade experiment.

\section{Low TI Cases}

The momentum thickness Reynolds number, $R e_{\theta}$, and the shape factor, $H$, were computed from the mean velocity profiles and are presented in Figure 4 for the low TI cases. At the upstream stations for all cases, $R e_{\theta}$ grows very slowly due to the strong acceleration. The three higher $R e$ cases show a jump at $s / L_{s} \approx 0.8$, which will be shown below to be
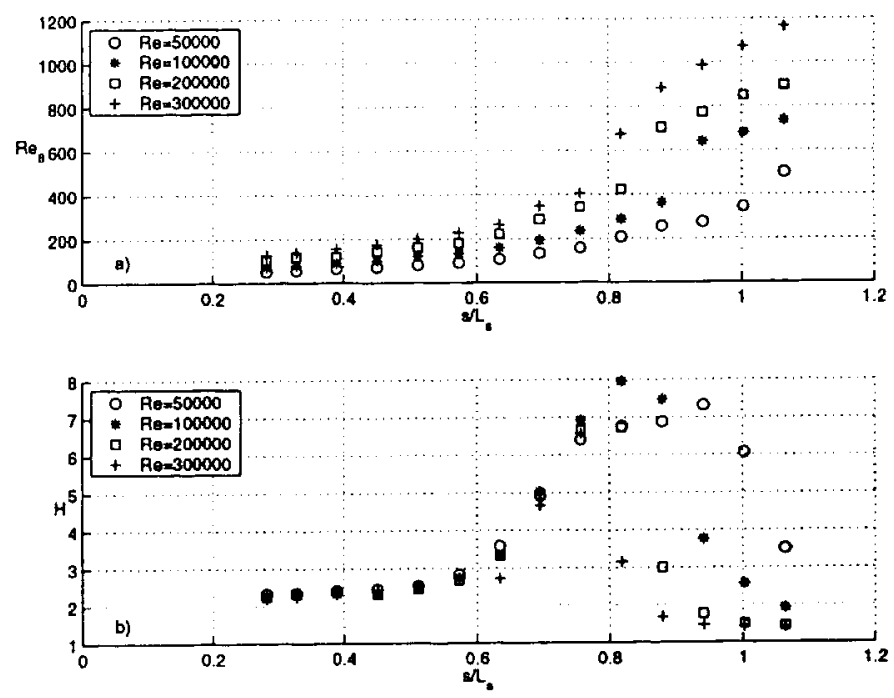

Figure 4. Momentum thickness Reynolds numbers (a); and shape factors (b) for Low TI cases

indicative of transition and reattachment. The shape factors begin at a laminar value of about 2.3 in all cases and remain near this level until the fifth station, which corresponds to the throat. Downstream of the throat, there is a sharp rise in $H$ for all cases due to a rise in the displacement thickness as the boundary layer separates. The $R e=300,000$ case returns to lower $H$ first, as the boundary layer reattaches. A fully turbulent value of $H=1.4$ is achieved by the 12th station. The $R e=200,000$ case just reaches $H=1.4$ at station 13 , which would correspond to the trailing edge of the airfoil. At the lower $R e$, the turbulent value is never achieved.

The mean streamwise velocity profiles, streamwise fluctuating velocity profiles and intermittency profiles are presented for all streamwise stations of the low TI, $R e=50,000$ case in Figure 5. The mean velocity profiles (Figure 5a) are normalized on the nominal free-stream exit velocity, which would correspond to the free-stream velocity at Station 13 if the boundary layer was attached there. Mean velocity shows the expected laminar boundary layer profile for the first five stations, up to the throat. At station 6, just past the throat, there is a hint of an inflection point near the wall, but the boundary layer may still be attached. At Stations 7 through 13 the boundary layer is clearly separated and the separation bubble is growing. At Station 14, the low, but non-zero velocity near the wall indicates that the boundary layer is reattaching, although it may be intermittently separated and attached. Since Station 13 represents the end of the airfoil in question, the mean velocity profiles indicate that the boundary layer would not reattach on the airfoil at this $R e$ and TI. 

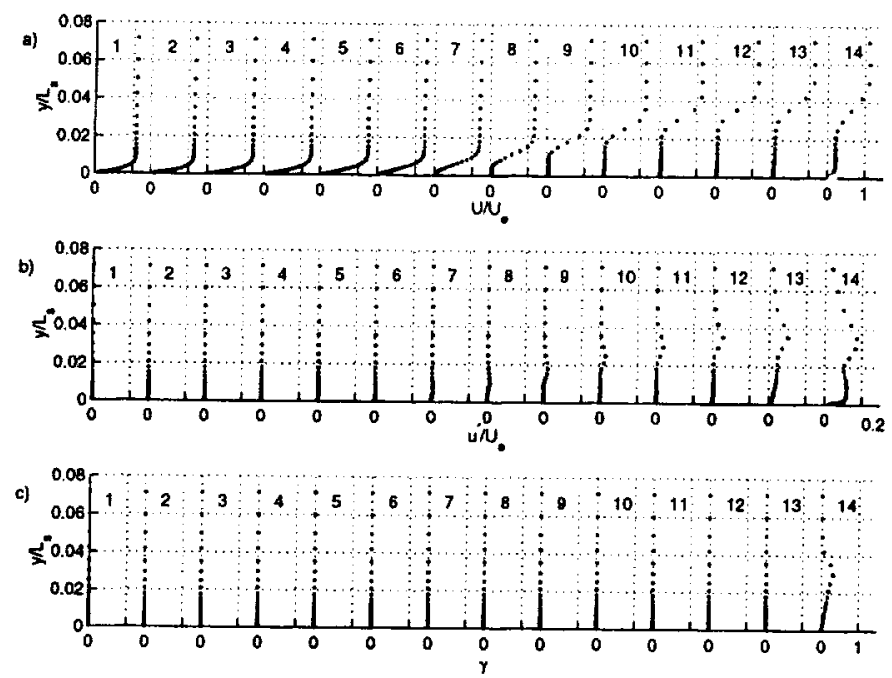

Figure 5. Profiles for $\mathrm{Low} T \mathrm{TI}, \mathrm{Re}=50,000$ case: a) Mean velocity, b) Turbulence, c) Intermittency

The fluctuating velocity profiles (Figure $5 \mathrm{~b}$ ) show very low turbulence at the first six stations, as expected for an accelerated laminar boundary layer subject to very low freestream turbulence. At Station 7, there is a slight increase in $u^{\prime}$ just above the separation bubble seen in the mean profile. The $u^{\prime}$ fluctuations continue to grow in the shear layer over the separation bubble at Stations 8 through 12. The $u^{\prime}$ level is still very low inside the bubble, indicating that the flow is largely stagnant in this region. This is expected based on the near-zero mean velocity in the separation bubble. Since the hot-wire can not distinguish flow direction, a reversing or turbulent flow in the separation bubble would have resulted in false positive mean velocity if the magnitude of the fluctuations were significant. At Station $13, u^{\prime}$ continues to grow in magnitude, and significant fluctuations also begin to appear near the wall. This may indicate that the boundary layer is starting to reattach. The fluctuations are also extending farther from the wall toward the free-stream. By the last station, the $u^{\prime}$ profile shows a double peak, with a high value near the wall and a second peak in the shear layer. The near wall peak indicates that an attached turbulent or transitional boundary layer is developing.

Intermittency profiles are shown in Figure 5c. The intermittency was computed from the digitized instantaneous streamwise velocity signal. Turbulent flow is classified as flow containing fluctuations over a broad band of frequencies, including high frequencies. This choice deliberately includes as turbulent the typical fluctuations associated with a turbulent boundary layer, but excludes the fluctuations associated with free-stream unsteadiness or narrow frequency band unsteadiness in a shear layer. While this definition is used in the present study, it is recognized that other researchers might choose different definitions of "turbulence." The signal was digitally high-pass filtered to eliminate fluctuations associated with the free-stream unsteadiness and any coherent motion (instability waves) in the shear layer of the separation bubble. Both the freestream induced fluctuations and the instability waves occur at relatively low frequencies compared to 'true' turbulence which occurs over a wide range of scales, resulting in both high and low frequency fluctuations. The filter frequency was varied linearly with $R e$, and was set at $750 \mathrm{~Hz}$ for the $R e=50,000$ cases. This filter cuts most of the turbulence, along with the other fluctuations, but passes enough of the high frequency tail of the turbulence spectrum to allow determination of the intermittency. The first and second time derivatives of the filtered signal are computed and compared to thresholds. When either derivative is above its threshold, the flow is declared turbulent at that particular instant in time. The thresholds are set based on the local velocity at the measurement point and the free-stream velocity at that station. The comparison of time derivatives to thresholds is a standard technique documented in such studies as Hedley and Keffer (1974) and Kim et al. (1994). The high-pass filtering is believed to be new, and is needed in the present study to separate the turbulence from other fluctuations in the boundary layer. In a low TI attached boundary layer such filtering is not needed, as shown in studies such as Kim et al. (1994). Volino (1998a) computed intermittency for a high TI attached boundary layer based on the turbulent shear stress, $-u^{\prime} v^{\prime}$. The shear stress, in that situation, is primarily attributable to turbulent mixing, as opposed to other fluctuations induced in the boundary layer, and therefore serves as a good basis for intermittency determination, without the need for filtering. The present scheme allows intermittency determination from a single velocity component and rejects coherent motions in the shear layers of separation bubbles. The uncertainty in intermittency is $7 \%$. Further details are available in Hultgren and Volino (2000).

The profiles in Figure 5c show a non-turbulent flow for the first thirteen stations. The upstream stations are laminar. Over the separation bubble, the fluctuations due to shear layer instability have not resulted in broadband turbulence. Only at the most downstream station, as the boundary layer begins to reattach and fluctuating velocities become significant near the wall, does transition begin. Peak intermittency is $31 \%$ at this station, and the peak is away from the wall in the shear layer.

Results for the $R e=300,000$, low TI case are shown in Figure 6, in the same format as Figure 5. The mean-velocity profiles show an attached laminar boundary layer for the first seven stations. The $R e=50,000$ case started to show 

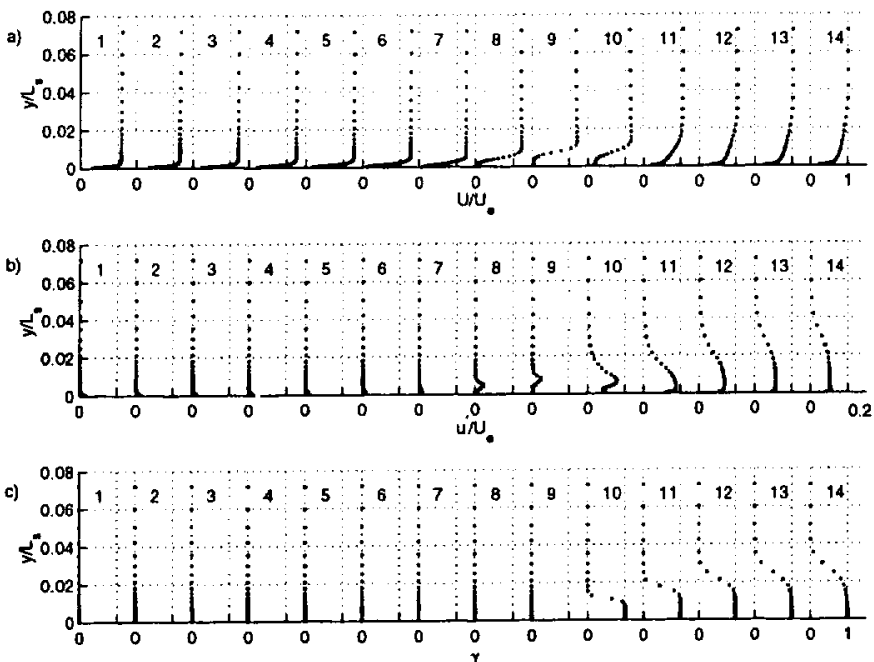

Figure 6. Profiles for Low TI, $R e=300,000$ case: a) Mean velocity, b) Turbulence, c) Intermittency

signs of separation already at Station 6 , but the higher $R e$ reduces the dimensionless acceleration parameter, $K$, by a factor of six, making the boundary layer more resistant to separation. At Station 8, the boundary layer is separated and the separation bubble has grown at Station 9. By Station 10 , the near wall velocity has increased, indicating the beginning of reattachment. By Station 11, reattachment appears complete, and the boundary layer recovers over the remaining stations to a fully-developed turbulent profile.

The fluctuating velocities are at low, laminar levels over the first seven stations. A very low magnitude near wall peak is present in $u^{\prime}$, which is typical of a laminar boundary layer under low TI conditions. At Station 8 there is an increase in $u^{\prime}$ in the shear layer as the boundary layer begins to separate. These fluctuations are due to a shear layer instability, and were observed in the hot-wire signal to occur at a coherent frequency. They increase in strength at Station 9, and result in the rapid breakdown to turbulence at Station 10, as the boundary layer begins to reattach. Station 10 shows a double peak, with a smaller peak in the near wall region, presumably due to near wall generated turbulence, and a larger peak away from the wall, caused by the breakdown of the shear layer instability. At the downstream stations, the $u^{\prime}$ profile adjusts to the expected fully-turbulent, attached boundary layer shape. Figure 7 shows boundary layer spectra from the location of maximum $u^{\prime}$ from several stations. The peak at $1400 \mathrm{~Hz}$ which appears at Station 8 is due to the shear layer instability. The frequency agrees with theoretical estimates. The 1400 $\mathrm{Hz}$ peak increases in magnitude and two higher harmonics appear at $2800 \mathrm{~Hz}$ and $4200 \mathrm{~Hz}$ at Station 9. At other

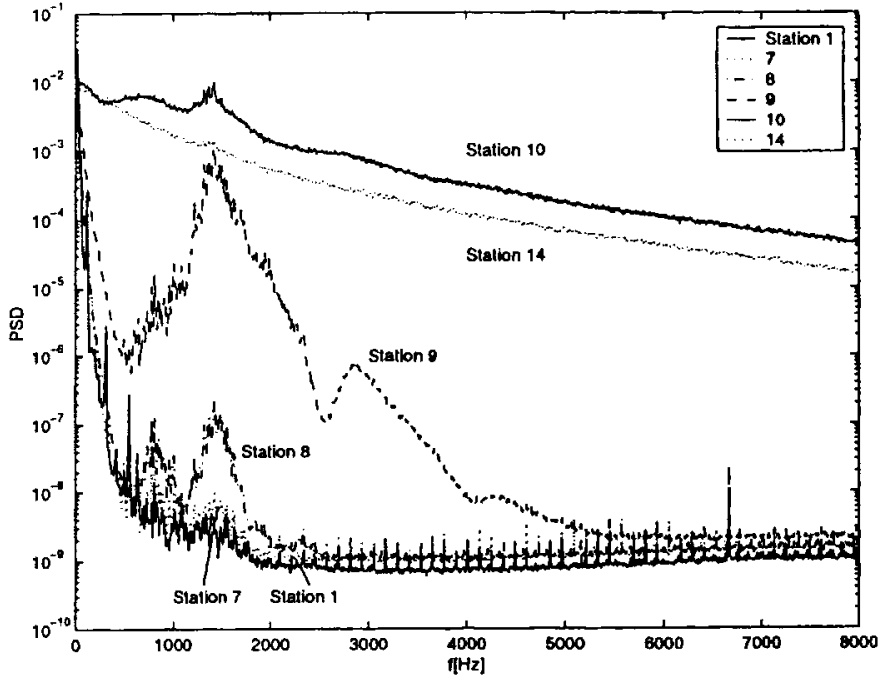

Figure 7. Boundary layer $u^{\prime}$ spectra at locations of maximum $u^{\prime}$, Low TI, $\operatorname{Re}=300,000$ case

frequencies the magnitude is still low, indicating that the boundary layer is not yet turbulent. Between Stations 9 and 10 there is a sudden jump to higher levels at all frequencies, indicating a transition to turbulence. The peak at $1400 \mathrm{~Hz}$ is still visible above the turbulence until Station 13. Similar spectral behavior was observed in the lower $R e$ cases.

The intermittency profiles (Figure 6c) show nonturbulent flow for the first nine stations, then a sudden appearance of fully-turbulent flow at Station 10, as the intermittency jumps to $100 \%$. This sudden jump in intermittency was also seen in the $R e=100,000$ and 200,000 cases at the low TI. Transition is clearly induced by the unsteadiness in the shear layer. The results agree with those of Malkiel and Mayle (1996) who also reported a rapid rise in intermittency over the shear layer. Presumably, if more measurement stations had been concentrated between the present Stations 9 and 10, the growth of intermittency from 0 to $100 \%$ could have been documented.

Skin friction coefficients were determined from the mean velocity profiles, and are presented for all the low TI cases in Figure 8 as $c_{f}$ vs $R e_{\theta}$. Also shown for reference are laminar and turbulent correlations for low TI, zero pressure gradient boundary layers on flat plates. The $c_{f}$ values for the attached laminar profiles were determined by profile fitting, using the technique of Volino and Simon (1997b). This technique accounts for the effect of non-zero pressure gradient on profile shape, and allows a fit of most of the profile, including the near wall region but not the wake. The same technique was also applied for the downstream stations, where the profile had recovered from separation to 


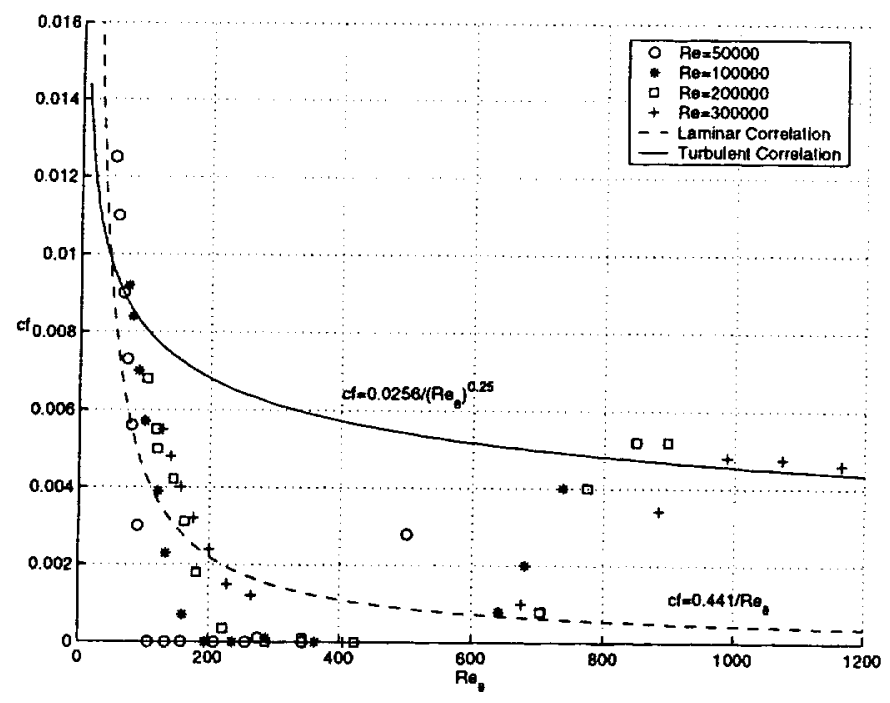

Figure 8. Skin friction coefficient vs $R e_{\theta}$ for Low $\mathrm{TI}$ cases

a fully-developed turbulent shape. In these cases the uncertainty in $c_{f}$ was $10 \%$. Under the separation bubble, $c_{f}$ was assumed to be zero. Determining $c_{f}$ was most difficult in the region just downstream of reattachment. Here the boundary layer was believed to be intermittently separated and attached, and the profile included a pronounced defect, which was a remnant of the separation bubble. In this region $c_{f}$ was determined by fitting only the very near wall profile, with an uncertainty of $30 \%$. The $R e=200,000$ and 300,000 cases show good agreement with the zero pressure gradient turbulent correlation by the downstream stations.

\section{High TI Cases}

The $R e_{\theta}$ and $H$ distributions for the high TI cases are shown in Figure 9. The momentum thickness grows slowly at the upstream stations and is equal to or just slightly larger than the corresponding cases at low TI (Figure 4). This is expected; the high TI promotes slightly faster boundary layer growth. The high TI cases do not show the jump in $R e_{\theta}$ observed in the low TI cases after reattachment. At the downstream stations, $R e_{\theta}$ are lower for the high TI case, at about $70 \%$ of the low TI values. As will be shown below, the separation bubbles are smaller at the high TI, resulting in thinner boundary layers after reattachment. The shape factors begin at the laminar value of about 2.3, as in the low TI cases, and rise as the boundary layer separates. The $H$ values do not rise to the high levels of the low TI case, again because the separation bubbles are not as thick, resulting in considerably lower displacement thicknesses. Fully-turbulent attached boundary layer values of about 1.4 are achieved in the three higher $R e$ cases,
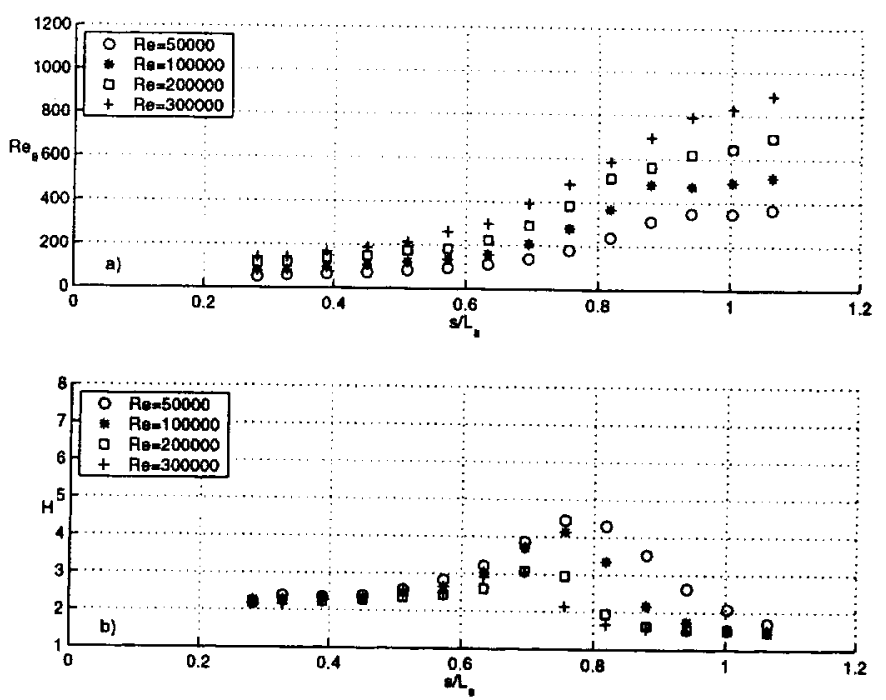

Figure 9. Momentum thickness Reynolds numbers (a); and shape factors (b) for High $\mathrm{TI}$ cases
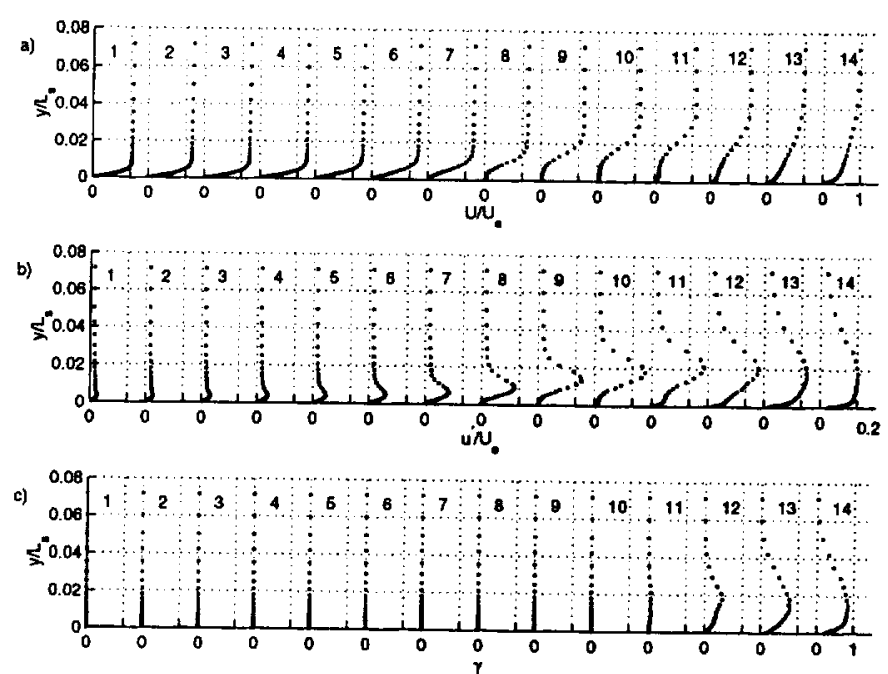

Figure 10. Profiles for High TI, $\mathrm{Re}=50,000$ case: a) Mean velocity, b) Turbulence, c) Intermittency

upstream of the locations for the low TI case. Even the $R e=50,000$ case comes close to $H=1.4$ by the last station.

The velocity profiles for the $R e=50,000$ case are shown in Figure 10. The mean profiles appear very similar to the $R e=50,000$, low TI case (Figure 5) for the first seven stations. At Station 7, the laminar boundary layer begins to separate. At Stations 8, 9 and 10, the boundary layer is separated, but the thickness of the separation bubble is only about half that of the low TI case at the same stations. At Station 11, the boundary layer has begun to reattach, 
and at Stations 12,13 , and 14 , the profile shape recovers to that of an attached turbulent boundary layer. In the low TI case, reattachment did not occur until Station 14 .

The $u^{\prime}$ profiles show a near-wall peak of about $3 \%$ of the mean free-stream velocity even at the most upstream station. These $u^{\prime}$ fluctuations in the non-turbulent boundary layer are primarily of low frequency and are induced by the free-stream fluctuations, as described in Blair (1992) and Volino (1998b). The near wall peak grows slowly, but steadily through Station 6. At Stations 7 through 10, the peak moves away from the wall and into the shear layer over the separation bubble. No coherent frequencies were observed in the hot-wire signal in the shear layer. Any instabilities similar to those in the low TI case appear to be overwhelmed by the free-stream turbulence induced phenomena. At Station 10 , the peak $u^{\prime}$ is $26 \%$ of the freestream velocity. At Station 11, the fluctuation levels rise near the wall, as the boundary layer begins to reattach. By Station 14, the $u^{\prime}$ profile looks like that of an attached turbulent boundary layer, but the peak $u^{\prime}$ is still higher (at $20 \%$ of $U_{e}$ ) than for a fully developed turbulent boundary layer. This indicates that the recovery from separation is not yet complete.

The intermittency is zero at the first ten stations in spite of the high TI. At Station 11 transition has begun, corresponding to the beginning of reattachment. The peak intermittency increases from $7 \%$ at Station 11 to $47 \%$ at Station 12. The peak is away from the wall, indicating that transition is initiated in the shear layer over the separation bubble. Transition occurs upstream of its location in the $R e=50,000$, low TI case. Spectral results, which are qualitatively similar to those shown below in Figure 12 (high TI, $R e=300,000$ case) show no amplification of select instabilities as in Figure 7 (low TI, $R e=300,000$ case), but rather a rising energy level across the entire spectrum as transition proceeds. This indicates that transition occurs through a bypass mode, rather than the breakdown of the instability waves seen in the low TI case. The intermittency reaches $85 \%$ by the last station.

The high TI, $R e=300,000$ profiles are shown in Figure 11. The profiles show good agreement with the low TI case (Figure 6) through Station 7. At Station 8, the high TI case is on the verge of separation, whereas the low TI case already showed a small but clear separation bubble. At Station 9, the high TI boundary layer is clearly attached, and continues to develop as an attached turbulent boundary layer at the further downstream stations. Hence, the combination of high $R e$ and high TI prevents separation in this case or a least limits it to a very small separation region.

The fluctuating velocity profiles are similar to the $R e=50,000$, high TI case for the first six stations, showing significant $u^{\prime}$ due to the action of the free-stream turbulence
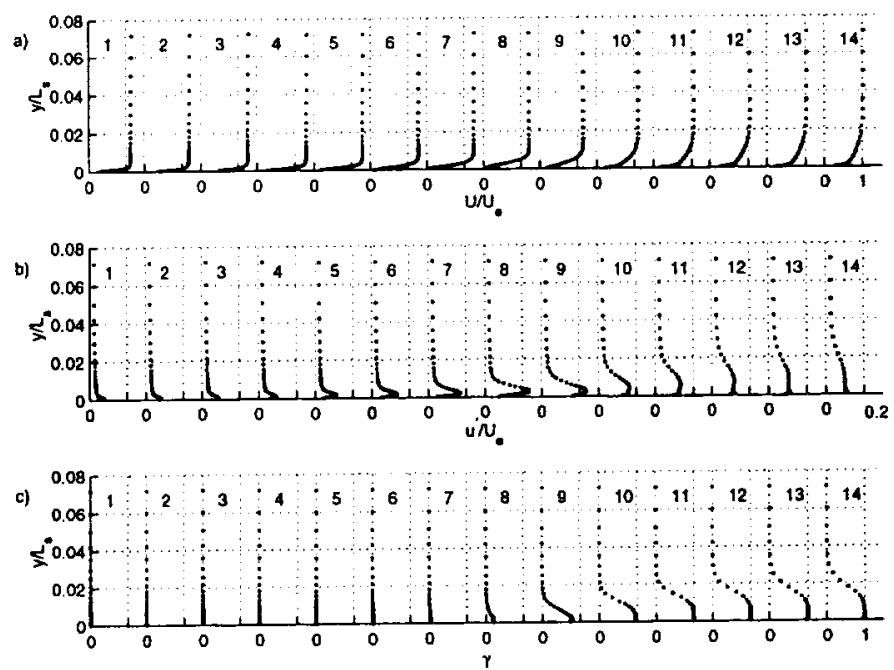

Figure 11. Profiles for High TI, $R e=300,000$ case: a) Mean velocity, b) Turbulence, c) Intermittency

on the boundary layer. At Stations 7 through 9 , the $u^{t}$ level increases substantially to a peak value of $23 \%$ of the mean free-stream velocity. Downstream of this the peak $u^{\prime}$ drops to $11 \%$ of the free-stream velocity, and the profile assumes a turbulent shape. The transition process is typical of a high TI attached boundary layer transition.

The intermittency profiles show non-turbulent flow for the first six stations. Transition has started at Station 7, with a peak intermittency of $5 \%$, and continues at Stations 8 and 9 . By Station 10 the intermittency is near $100 \%$, and by Station 11 transition is complete. Transition begins just downstream of the throat, which is well upstream of the transition start in the low TI, $R e=300,000$ case (Figure 6). If there is a small separation region, it occurs downstream of the onset of transition. Transition end occurs at about the same location in the high and low TI cases.

Figure 12 shows spectra at the locations of maximum $u^{\prime}$ in the boundary layer. Comparing to Figure 7, there is considerably more fluctuation energy in the high TI case at the upstream stations than in the low TI case. This energy is induced by the free-stream over all frequencies, with no frequency spikes. However, comparing to Figure 3, it is clear that the lower frequencies are more successful in penetrating the upstream boundary layer. The energy level rises gradually from Station 1 through 7 , then rises more rapidly as the flow goes through transition. Downstream of transition, the spectra for the low and high TI cases are essentially the same.

Skin friction coefficients are plotted vs $R_{\theta}$ in Figure 13. The upstream stations are very similar to those at low TI (Figure 8). Downstream there is good agreement with 


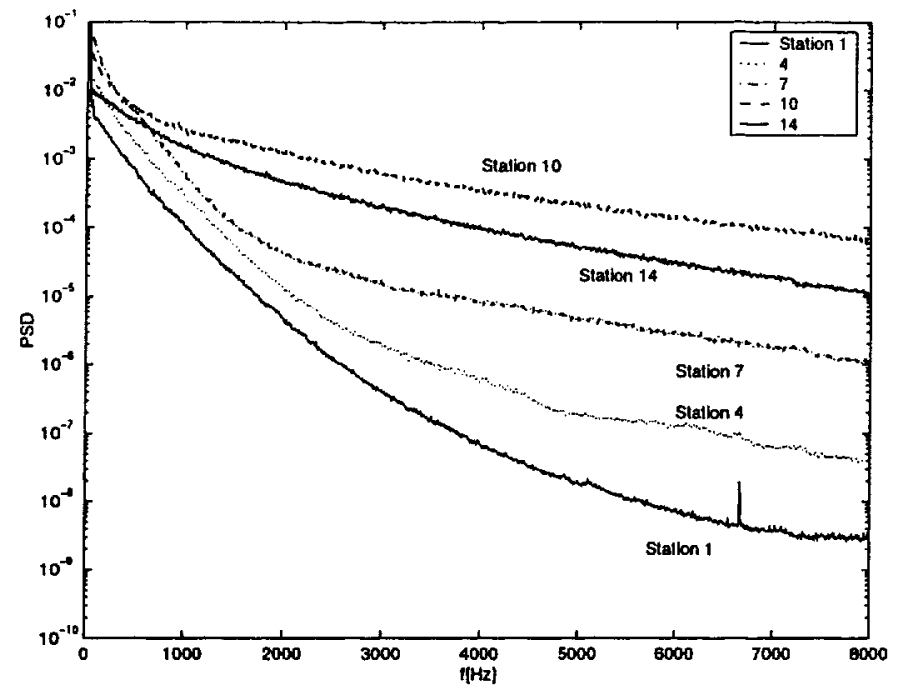

Figure 12. Boundary layer $u^{\prime}$ spectra at locations of maximum $u^{\prime}, \mathrm{High} \mathrm{TI}$, $\mathrm{Re}=300,000$ case

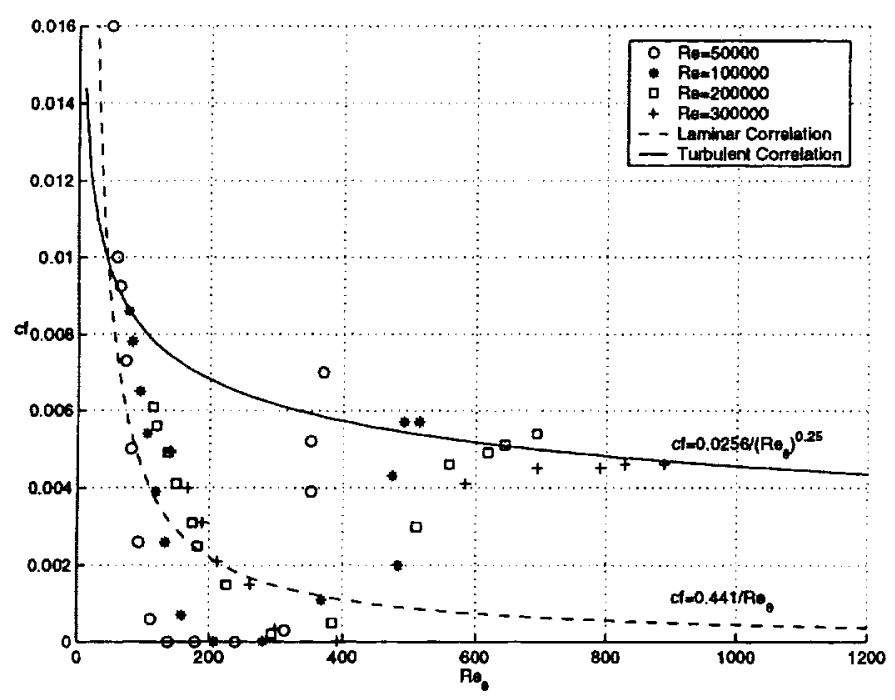

Figure 13. Skin friction coefficient vs $R e_{\theta}$ for High Tl cases

the zero-pressure-gradient turbulent boundary layer correlation.

\section{Transition and Separation Locations}

The locations of separation, reattachment, and transition start and end are tabulated in Table 2. Locations are given as distance from the leading edge normalized on $L_{s}$ and in terms of $R e_{\theta}$. Separation location is estimated by extrapolating the separation bubble thickness upstream to the point of zero thickness. Reattachment was observed to oc-
Table 2. Separation and Transition Locations: $s=s e p a r a t i o n, ~ t s=t r a n s i t i o n$ start, $r=$ reattachment, te $=$ transition end.

\begin{tabular}{|c|c|c|c|}
\hline$R e$ & $\mathrm{~s}$ & $\begin{array}{c}\text { ts and } \mathrm{r} \\
\left(s / L_{s}\right) / R e_{\theta}\end{array}$ & $\begin{array}{c}\text { te } \\
\left(s / L_{s}\right) / R e_{\theta}\end{array}$ \\
\hline Low TI & & & - \\
50000 & $0.63 / 106$ & $1.0-1.06 / 344-501$ & - \\
100000 & $0.66 / 177$ & $0.88-0.94 / 363-642$ & $0.94-1.0 / 642-680$ \\
200000 & $0.67 / 260$ & $0.76-0.82 / 344-423$ & $0.82-0.88 / 423-704$ \\
300000 & $0.67 / 314$ & $0.76-0.82 / 406-675$ & $0.76-0.82 / 406-675$ \\
\hline High TI & & & \\
50000 & $0.63 / 111$ & $0.85 / 271$ & $1.11 / 383$ \\
100000 & $0.63 / 158$ & $0.78 / 230$ & $0.92 / 477$ \\
200000 & - & $0.72 / 322$ & $0.85 / 533$ \\
300000 & - & $0.66 / 336$ & $0.82 / 592$ \\
\hline
\end{tabular}

cur simultaneously with transition onset. Transition occurs abruptly in the low TI cases, and its location can only be estimated to within the station spacing, so a range is given for the transition start and end locations in Table 2. At the high TI there are enough stations within the transition region to extrapolate to the beginning and end of transition using the technique presented by Narasimha (1984). As explained in Volino and Simon (1995), the function

$$
f\left(\gamma_{p k}\right)=\left[-\ln \left(1-\gamma_{p k}\right)\right]^{1 / 2}, \gamma_{p k}=\gamma_{p k}(s)
$$

is computed from the peak intermittency at each streamwise station and plotted vs streamwise location. A line is then fit through the points for each case and extrapolated to $f\left(\gamma_{p k}\right)=0$ to determine the start of transition location, and to $f\left(\gamma_{p k}\right)=2.146$, which corresponds to $\gamma_{p k}=0.99$, to determine the end of transition location. Intermittency is plotted vs position within the transition zone in Figure 14 along with a theoretical line from Dhawan and Narasimha (1958). Although the theoretical line is associated with attached flow transition, agreement is still good for the separated flow cases, as expected by Narasimha (1998).

Comparison to correlations. Transition begins in all the high TI cases at $R e_{\theta}$ between 250 and 350. Correlations by Abu-Ghannam and Shaw (1980) and Mayle (1991) for attached flow transition predict transition start at about $R e_{\theta}=250$ for $2.5 \% \mathrm{TI}$, which is the free-stream turbulence level over the test wall. The agreement with the correlations suggests that the attached flow bypass transition cor- 


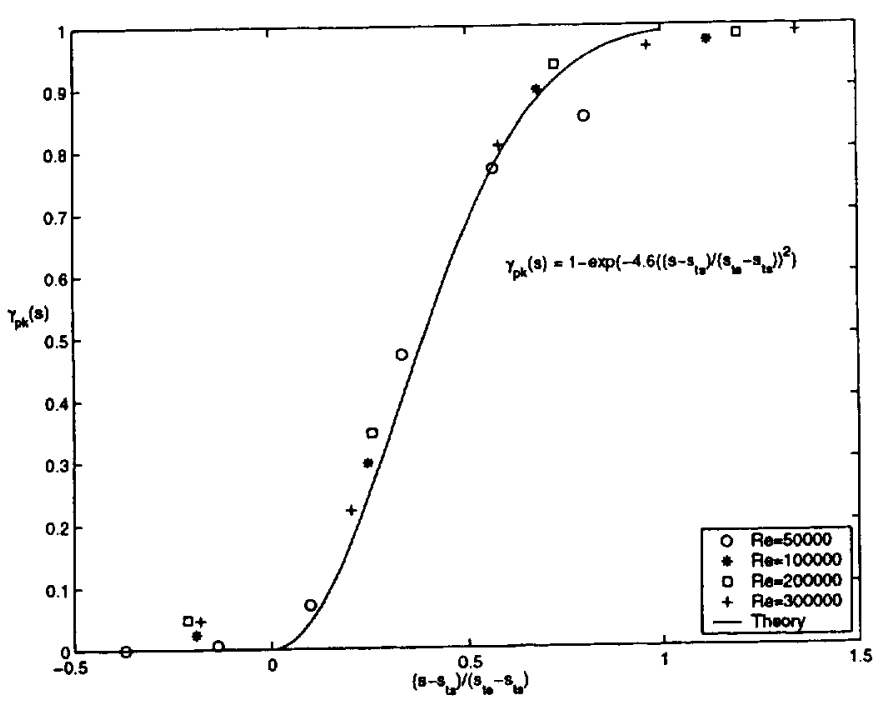

Figure 14. Peak intermittency distributions for High TI cases

relations may be useful at high TI, even in cases with separation. The correlations predict transition end at $R e_{\theta}$ of about 600 , which agrees with the $R e=300,000$ case. The velocity profiles for this case show that there may be a small separation region, but the flow is essentially behaving as an attached boundary layer. The lower $R e$ cases complete transition at lower $R e_{\theta}$ than the correlations predict.

At the low TI, the Abu-Ghannam and Shaw (1980) correlation predicts transition start and end at $R e_{\theta}$ of 900 and 2,600 respectively for $0.2 \%$ TI. Transition occurs at much lower $R e_{\theta}$ in the experiments, showing that the attached flow correlations are not useful for low TI separated flow transition.

Separation is expected in laminar boundary layers when the pressure gradient parameter $\lambda_{\theta}=-0.082$, as given by Thwaites (1949). To within the resolution of the station locations in the present experiments, this correlation holds. When separation occurs before the start of transition, Mayle (1991) suggests the following correlations for the start of transition.

$$
\begin{aligned}
& R e_{s t}=300 R e_{\theta s}^{0.7} \quad \text { (short bubbles) } \\
& R e_{s t}=1000 R e_{\theta s}^{0.7} \quad \text { (long bubbles) }
\end{aligned}
$$

The present low TI cases have $R e_{s t}$ between the long bubble and short bubble correlations. The high TI cases are closer to the short bubble correlation. The $R e_{s t}$ values for the $R e=50,000$ and 100,000 high TI cases are $30 \%$ and $44 \%$ above Equation (2). The $R e=200,000$ and 300,000 high TI cases begin transition before separation, so the correlations are not applicable.

Mayle (1991) also provides the following correlation for the length of the transition region

$$
R e_{L T}=400 R e_{\theta s}^{0.7}
$$

The present $R e=50,000$ and 100,000 high TI cases agree with this correlation to within $20 \%$. In the low TI cases, the resolution of the transition start and end locations is limited by the station spacing, resulting in large uncertainties in $R e_{L T}$. The upper end of the uncertainty bands for these cases lie within $25 \%$ of Equation (4).

Davis et al. (1985) provide the following correlation for $R e_{s t}$ which takes free-stream turbulence effects into account

$$
R e_{s t}=25000 \log [\operatorname{coth}(17.32 T I)]
$$

where $\mathrm{TI}$ is given as a fraction of the local free-stream velocity. Equation (5) predicts $R e_{s t}$ of 9,800 and 36,000 for the high and low TI cases respectively. The low TI prediction is within about $30 \%$ of the present exprimental results. The high TI prediction is too low by between $30 \%$ and $50 \%$ of the experimental results.

\section{Comparison to Previous Study}

The results presented above are very similar to those presented by Qiu and Simon (1997) for boundary layers subject to the same nominal pressure gradient in a single passage cascade. An examination of the shapes of the mean velocity, $u^{\prime}$ and intermittency profiles shows similarity between the studies. There are some differences, however, in the locations of separation and transition. In the present study, separation occurred at $s / L_{s}$ between 0.63 and 0.67 . Qiu and Simon (1997) reported locations further upstream, at $s / L_{s}=0.54$ for $2.5 \%$ and $10 \% \mathrm{TI}$, and between 0.46 and 0.54 for their $0.5 \% \mathrm{TI}$ case. The $s / L_{s}=0.54$ location is immediately downstream of the throat. Some of the differences in separation location between the present study and Qiu and Simon (1997) may be due to curvature effects. Since separation depends strongly on the streamwise pressure gradient, it is also possible that these differences might be due to slight differences in the actual streamwise pressure gradients (even though nominally being the same) in the two studies, however.

Qiu and Simon (1997) also reported the start of transition further upstream than in the present study. In the present low TI cases, transition began near $s / L_{s}=1.0$ in the $R e=50,000$ case, and moved upstream with Reynolds 
number to $s / L_{s}=0.8$ when $R e=300,000$. Qiu and Simon (1997) reported locations between $s / L_{s}=0.68$ and 0.79 , also moving upstream with $R e$. At the high TI, Qiu and Simon (1997) reported $s / L_{s}$ of about 0.6 , while in the present study $s / L_{s}=0.8$. Transition end behavior was similar, with Qiu and Simon (1997) reporting $s / L_{s}$ values about 0.1 less than the present study. Since separation strongly influences transition, the differences in separation location between the two studies may explain the differences in transition location. Another possible explanation for the differences in transition location is the way in which intermittency was determined. Qiu and Simon (1997) did not filter (apart from anti-aliasing low-pass filtering) their hot-wire signal, while in the present study the digitized velocity signal was also high-pass filtered before the intermittency determination, as described above. It is possible that some of what Qiu and Simon (1997) considered turbulence was due to free-stream induced unsteadiness and instability waves. This would have resulted in higher intermittency values at all locations, which would have indicated both transition start and end locations farther upstream than in the present study.

Reattachment occurred in the present study at the same location as the onset of transition, and the locations agree closely with those given by Qiu and Simon (1997), to within $s / L_{s}$ of 0.03 in most cases. The good agreement in reattachment location between the studies contrasts with the differences in transition end location, and supports the conclusion that the apparent differences in transition zone location may be due at least in part to differences in intermittency processing as opposed to physical differences in transition location.

\section{CONCLUSIONS}

Boundary layer separation, transition and reattachment have been documented under Reynolds number and pressure gradient conditions typical of low-pressure turbine airfoils. Reynolds number and free-stream turbulence level do not have a significant effect on boundary layer separation unless they are high enough to induce transition upstream of separation. The location and extent of the transition zone, in contrast, depend strongly on $R e$ and TI. The beginning of reattachment occurs simultaneously with the onset of transition. Under low free-stream turbulence conditions the boundary layer is laminar at separation and then begins to exhibit fluctuations in a finite frequency band in the shear layer over the separation bubble. These fluctuations are due to instability waves. The fluctuations grow in magnitude, higher harmonics are generated, and finally lead to a breakdown to turbulence. Transition begins in the shear layer, but quickly spreads to the near wall region and causes the boundary layer to reattach. The transition is rapid and the resulting turbulence contains a full range of high and low frequencies. Under high free-stream turbulence conditions, slowly growing low-frequency fluctuations are induced in the pre-transitional boundary layer by the free-stream, e.g. Dryden (1936), Blair (1992), and Volino (1998a). Separation bubbles are considerably thinner than in the low TI cases, resulting in thinner boundary layers at the end of the test wall. At $\operatorname{Re}=50,000$ and 100,000 , the pre-transitional boundary layer separates at about the same location as in the low TI cases. Transition occurs through a bypass mode and begins upstream of the locations in the corresponding low TI cases. The transition proceeds in a manner more similar to an attached boundary layer than in the low TI cases. Under high TI at $\mathrm{Re}=200,000$ and 300,000 , transition begins before separation. The boundary layer may separate, but if it does the separation bubble is very short and does not significantly affect the downstream development of the boundary layer.

The documentation of attached and separated boundary layers should provide good test cases for further model development. Future processing of the data, including detailed spectral analysis will provide further insight into the nature of the boundary-layer behavior in these cases.

\section{ACKNOWLEDGMENT}

The first author was supported by the NASA/ASEE Summer Faculty Fellowship program with matching support through a U.S. Naval Academy Recognition Grant. The work was done under the NASA Low Pressure Turbine Flow Physics Program managed by Dr. David Ashpis and the NASA Turbomachinery and Combustion Technology Program managed by Kestutis Civinskas.

\section{REFERENCES}

Abu-Ghannam, B.J. and Shaw, R., 1980. "Natural Transition of Boundary Layers - The Effects of Turbulence, Pressure Gradient and Flow History," Journal of Mechanical Engineering Science, Vol. 22, pp. 213-228.

Blair, M. F., 1992, "Boundary-Layer Transition in Accelerating Flow With Intense Freestream Turbulence: Part 1-Disturbances Upstream of Transition Onset," J. Fluids Engineering, Vol. 114, pp. 313-321.

Chernobrovkin, A. and Lakshminarayana, B., 1999, "Turbulence Modeling and Computation of Viscous Transitional Flow for Low Pressure Turbines," Proceedings of the 4th International Symposium on Engineering Turbulence Modeling and Measurements, Corsica, France.

Davis, R.L., Carter, J.E. and Reshotko, E., 1985, 
"Analysis of Transitional Separation Bubbles on Infinite Swept Wings," AIAA paper 85-1685.

Dhawan, S. and Narasimha, R., 1958, "Some Properties of Boundary Layer Flow During the Transition from Laminar to Turbulent Motion," Journal of Fluid Mechanics, Vol. 3 , pp. $418-436$.

Dorney, D.J., Ashpis, D.E., Halstead, D.E. and Wisler, D.C., 1999, "Study of Boundary Layer Development in a Two-Stage Low-Pressure Turbine," AIAA paper 99-0742, also NASA/TM-1999-208913.

Dryden, H.L., 1936, "Air flow in the boundary layer near a plate," NACA Report 562.

Halstead, D.E., Walker, G.J., Wisler, D.C., Hodson, H.P., Okiishi, T.H. and Shin, H.-W., 1997, "Boundary Layer Development in Axial Compressors and Turbines: Part 3 of 4 - LP Turbines," ASME Journal of Turbomachinery, Vol. 119, pp. 234-246.

Hatman, A. and Wang, T., 1999, "A Prediction Model for Separated-Flow Transition," ASME Journal of Turbomachinery, Vol. 121, pp. 594-602.

Hedley, T.B. and Keffer, J.F., 1974, "Turbulent/NonTurbulent Decisions in an Intermittent Flow," Journal of Fluid Mechanics, Vol. 64, pp. 625-644.

Hourmouziadis, J., 1989, "Aerodynamic Design of Low Pressure Turbines," AGARD Lecture Series, 167.

Huang, P.G. and Xiong, G., 1998, "Transition and Turbulence Modeling of Low Pressure Turbine Flows," AIAA paper 98-0039.

Hultgren, L.S. and Volino, R.J., 2000, "Measurements in Separated and Transitional Boundary Layers under LowPressure Turbine Airfoil Conditions," NASA TM, to be published.

Kim, J., Simon, T.W. and Russ, S.G., 1992, "FreeStream Turbulence and Concave Curvature Effects on Heated Transitional Boundary Layers," ASME Journal of Heat Transfer, Vol. 114, pp. 338-347.

Kim, J., Simon, T.W. and Kestoras, M., 1994, "Fluid Mechanics and Heat Transfer Measurements in Transitional Boundary Layers Conditionally Sampled on Intermittency," ASME Journal of Turbomachinery, Vol. 116, pp. 405-416.

Malkiel, E. and Mayle, R.E., 1996, "Transition in a Separation Bubble," ASME Journal of Turbomachinery, Vol. 118 , pp. $752-759$.

Mayle, R.E., 1991, "The Role of Laminar-Turbulent Transition in Gas Turbine Engines," ASME Journal of Turbomachinery, Vol. 113, pp. 509-537.

Morkovin, M. V., 1978, "Instability, Transition to Turbulence and Predictability," NATO AGARDograph No. 236.

Murawski, C.G., Sondergaard, R., Rivir, R.B., Simon, T.W., Vafai, K. and Volino, R.J., 1997, "Experimental Study of the Unsteady Aerodynamics in a Linear Cascade with Low Reynolds Number Low Pressure Turbine Blades," ASME paper 97-GT-95.

Narasimha, R., 1984, "Subtransitions in the Transition Zone," Proceedings of the 2nd IUTAM Symposium on Laminar-Turbulent Transition, Novosibirsk, pp. 141-151.

Narasimha, R., 1998, "Post-Workshop Summary," Minnowbrook II - 1997 Workshop on Boundary Layer Transition in Turbomachines, eds. LaGraff, J.E. and Ashpis, D.E., NASA CP 1998-206958, pp. 485-495.

Qiu, S. and Simon, T.W., 1997, "An Experimental Investigation of Transition as Applied to Low Pressure Turbine Suction Surface Flows," ASME paper 97-GT-455.

Sharma, O.P., Ni, R.H. and Tanrikut, S., 1994, "Unsteady Flow in Turbines," AGARD-LS-195, Paper No. 5.

Sohn, K.H. and Reshotko, E., 1991, "Experimental Study of Boundary Layer Transition with Elevated Freestream Turbulence on a Heated Flat Plate," NASA CR 187068.

Sohn, K.H., DeWitt, K.J. and Shyne, R.J., 1998, "Experimental Investigation of Boundary Layer Behavior in a Simulated Low Pressure Turbine," ASME paper 98-GT034.

Thwaites, B., 1949, "Approximate Calculations of the Laminar Boundary Layer," Aeronautical Quarterly, Vol. 7, pp. 245-280.

Volino, R.J. and Simon, T.W., 1995, "Bypass Transition in Boundary Layers Including Curvature and Favorable Pressure Gradient Effects," ASME Journal of Turbomachinery, Vol. 117, pp. 166-174.

Volino, R.J. and Simon, T.W., 1997a, "Boundary Layer Transition under High Free-Stream Turbulence and Strong Acceleration Conditions: Part 1: Mean Flow Results; Part 2: Turbulent Transport Results," ASME Journal of Heat Transfer, Vol. 119, pp. 420-432.

Volino, R.J. and Simon, T.W., 1997b, "Velocity and Temperature Profiles in Turbulent Boundary Layers Experiencing Streamwise Pressure Gradients," ASME Journal of Heat Transfer, Vol. 119, pp. 433-439.

Volino, R.J., 1998a, "Wavelet Analysis of Transitional Flow Data Under High Free-Stream Turbulence Conditions," ASME paper 98-GT-289.

Volino, R.J., 1998b, "A New Model for Free-Stream Turbulence Effects on Boundary Layers," ASME Journal of Turbomachinery, Vol. 120, pp. 613-620. 
